\title{
A questão da vida em Heidegger
}

\author{
The question of living in Heidegger
}

DOI: $10.20873 /$ rpv6n2-23

\section{Josiane Paula da Silva}

Orcid: 0000-0002-7696-0011

Email: josiane.paula@gmail.com

\begin{abstract}
Resumo
O horizonte da pergunta pela vida, em Heidegger, se dá no limite da compreensão da existência humana. Vida, para o filósofo, não é sinônimo de existência. Nosso artigo busca apresentar uma interpretação positiva possível desde essa caracterização negativa. Nesse intuito, evidenciamos, num primeiro momento, como a compreensão de si como ser-no-mundo, norteia e delimita a compreensão que o ser-aí tem dos animais e da vida (por extensão). Num segundo momento, desde o conceito de mundo, apresentamos, de modo resumido, a interpretação heideggeriana dos conceitos de organismo, órgão, aptidão e círculo de desinibição, hauridos pelo filósofo em suas investigações sobre a vida, em Os conceitos fundamentais da metafísica. Em um terceiro momento destacamos o modo como, para Heidegger, a originariedade da questão da vida provém do seu manter-se no horizonte de compreensão da nossa própria existência como questão, em oposição a uma interpretação da vida como algo simplesmente dado. Por fim, concluímos que a vida não se encerra, não tem fim, nos limites apresentados, mas que justamente se abre, é abertura; como questão, está sempre aberta e exige sempre, a cada vez, novas respostas.
\end{abstract}

\section{Palavras-chave}

Heidegger; vida; existência; mundo; questão.

\begin{abstract}
Heidegger's horizon in the quest for the meaning of Life relies on the limit of understanding human existence. As for the philosopher, Life is not a question of existence. Therefore, the following article aims to present a possible positive interpretation throughout this negative perspective. Hence, we have highlighted, at a first moment, how comprehension itself as being-in-the-world has guided and delimitated the comprehension that the being-there has had when concerning animals and life (as an extension). Ever since the concept of world, we have presented, in a few words, Heidegger's interpretation related to the concept of organisms, living organs, aptitude, and inhibition; these have been drawn by the philosopher in his investigations about life in Fundamental Concepts of Metaphysics. Thirdly, we have focused on the way Heidegger has seen authenticity in the question of time being, as it comes from its own keeping itself in the horizon of comprehension
\end{abstract}


of our own existence as a question, in opposition to a new interpretation of life as something present-at-hand. Finally, we have come to the conclusion that life is not ceased; it has no end within the boundaries we have observed; yet it is open and it is an opening. Thus, as a question, it has been opened and has increasingly demanded fresh responses.

\section{Keywords}

Heidegger; living; existence; world; question.

\section{Ser-no-mundo e a interpretação da vida}

Nosso artigo pretende apresentar o problema da vida orgânica para o filósofo alemão Martin Heidegger, desde uma comparação que o pensador faz em relação à existência, de acordo com o exposto em Ser e Tempo e, principalmente, em Os Conceitos fundamentais da metafísica, Mundo - Finitude - Solidão (1929/1930). Embora seja clara a distinção entre a existência do ente que nós somos e a vida, nas obras citadas, o que podemos encontrar é sempre a segunda, a questão da vida, de forma derivada em relação à primeira, à existência. Ou seja, Heidegger não coloca diretamente a questão da vida como problema, mas tão somente em relação a questão da existência. Isso por si só já nos dá uma pista do lugar da questão da vida no pensamento do autor e, por conseguinte, dos seus limites.

Em Os Conceitos fundamentais da metafísica, Mundo - Finitude - Solidão, Heidegger tece suas considerações sobre a vida no contexto da pergunta metafísica pelo mundo. Mundo, em Heidegger, é um fenômeno que constitui o ente que nós mesmos somos, ser-no-mundo, e determina fundamentalmente nossa existência. Ou seja, para o pensador, nós sempre já existimos em mundo, não como um lugar no qual fomos colocados, mas como estamos nos ocupando e nos preocupando em uma totalidade conjuntural em virtude dessa possibilidade mesma que somos: de nos ocupar e nos preocupar. Segundo Heidegger, "Como determinação fundamental de sua existência, o ser-no-mudo é o pressuposto para que se possa apreender efetivamente algo" (HEIDEGGER, 2012, p. 242). Ou seja, porque mundo constitui fundamentalmente nossa existência é que entes podem vir ao nosso encontro enquanto tais. 
Esse encontro com os entes, como podemos ver a partir do parágrafo 12 de Ser e Tempo, é possível desde a ocupação, no uso que fazemos deles. Heidegger nos mostra que descobrimos os entes, primária e originariamente, à medida que lidamos com eles em virtude do nosso existir e não em virtude do conhecimento que temos deles “[...] o modo mais imediato de lidar não é o conhecer meramente perceptivo e sim a ocupação no manuseio e uso, a qual possui um 'conhecimento' próprio" (HEIDEGGER, 2015, p. 115). Como assim? Quando nos sentamos para escrever um texto nós não apreendemos primeiro o que é uma cadeira, quais são suas propriedades e seus usos para então decidir nos sentarmos nela. Nós nos sentamos e pronto. Só vamos pensar na cadeira se, por algum motivo, ela não estiver em seu pleno uso: quando usamos ela como exemplo ou porque ela está machucando nossas costas. Isso significa que, para o pensador, é em virtude da possibilidade que somos que descobrimos os entes, mas é próprio do nosso modo de ser esquecermos disso e concebermos os entes de modo isolado, neles mesmos, indiferentes às ocupações que deles fazemos.

A apreensão originária dos entes na ocupação se dá devido ao seu caráter de manualidade (zuhandenheit). De acordo com Heidegger, a manualidade é “[...] o modo de ser do utensílio em que ele se revela por si mesmo" (2015, p. 117). Nesse modo de ser os entes não são apreendidos tematicamente, mas são desvelados à medida que deles fazemos uso. Heidegger usa o exemplo do martelo que só pode se dar originariamente e genuinamente no martelar. 0 martelar descobre mais originariamente o martelo do que qualquer tematização e descrição posterior que podemos fazer dele. No entanto, os termos utensílios, uso, e mesmo o exemplo do martelo, pode nos dar a impressão enganosa de que Heidegger está falando exclusivamente de ferramentas. A manualidade, o ente ser “a mão”, porém, não se limita àquilo que podemos manusear literalmente com as mãos, mas se aplica a todos os entes que entram na multiplicidade de referências de "ser para" (Um-zu). Ou seja, todo ente que vem ao nosso encontro nessa estrutura ser-para tem o modo de ser da manualidade. Nesse sentido não só a cadeira vem ao nosso encontro na ocupação e uso que dela fazemos, mas também o sol pode ser considerado um manual, uma vez que ele vem ao nosso encontro para nos aquecer, para secar a roupa, para medirmos o tempo etc. 
Os entes também são compreendidos, no entanto, de acordo com Heidegger, eu seu modo de ser simplesmente dado (vorhandenheit). Nesse modo de ser os entes são apreendidos como entes subsistentes em si mesmos, como indiferentes à multiplicidade de referências que o revelaram originariamente. É como simplesmente dados que os entes são tematizados e têm fixadas suas propriedades. A cadeira, por exemplo, uma vez retirada, em certo limite, da manualidade, é que passa ser cadeira, porque em nosso sentar-se ela nem mesmo aparecia enquanto cadeira. Uma vez nomeada cadeira ela pode então ser descrita enquanto tal. Esse modo de ser é que possibilita que nos refiramos aos entes como coisas que se dão simplesmente ao nosso redor, que subsistem independentemente da lida que temos com elas.

Essa apreensão dos entes como entes simplesmente dados se mostra como não originária, como uma derivada fixação das propriedades que o habilitaram para o uso. No entanto, é essa apreensão dos entes, de nós e de tudo mais (como entes simplesmente dados), que comumente sempre esteve à base quando se procurou pensar, de modo geral, em algo como a vida e, com essa questão, os seres vivos enquanto tais. Ou seja, como encerrando em si mesmos o sentido do seu ser, indiferente à nossa lida e nosso comportamento compreensivo enquanto tal. Mundo, nessa interpretação, se figura como um lugar onde estão todos os entes igualmente dispostos: vivos, não vivos e nós; e se tornou dispensável enquanto questão nas tradicionais investigações sobre vida e seres vivos.

\section{Mundo e animalidade}

Heidegger faz da caracterização da ligação com o mundo a via de acesso para uma diferenciação essencial entre o homem ${ }^{1}$, como existência, e do animal, como ser vivo. A partir dessa diferenciação e caracterização é que o pensador busca pensar o que seria a essência da vida. Vemos, assim, em Os conceitos fundamentais da metafísica, que, em comparação com o homem, que Heidegger diz ser formador de mundo, o animal é pobre de mundo e, coisas como pedras,

\footnotetext{
${ }^{1}$ Optamos por manter a tradução do Marco Casanova por homem, entendendo ser possível a compreensão e tradução por humano ou existente humano. Entendemos que o tradutor estabelece "homem" como substantivo neutro (atendendo à neutralidade ontológica do ser-aí, e não ao gênero gramatical em português) e reserva, via de regra, "humano" e semelhantes para qualificar o agir do ser-aí (homem) ao longo da obra.
} 
por exemplo, não têm mundo. Essa relação com mundo - a pobreza de mundo do animal - de acordo com o autor, diz mais fundamentalmente a essência dos animais do que qualquer tese específica da biologia até então. Pois,

[...] aquela tese não diz apenas algo sobre insetos ou mamíferos; ela também diz respeito, por exemplo, aos animais desprovidos de membros, aos animais unicelulares, às amebas, aos infusórios, ouriços do mar e similares - ela diz respeito a todo animal, a cada animal. (HEIDEGGER, 2003, p. 216)

Diríamos até que se refere aos animais que ainda poderiam ser descobertos, pois esta tese não fala desde a observação do que há de comum entre os animais, mas desde como os animais enquanto tais vêm ao nosso encontro. Tal tese, todavia, como uma proposição sobre animais, não é independente da biologia, mas também não se origina dela. Ela circunscreve um campo no interior do qual se move a biologia, como uma pressuposição. 0 que isso significa? Heidegger diz que as ciências de modo geral, e a biologia em particular, não tem fixos e imutáveis seus fundamentos, mas sofrem transformações importantes naquilo que compreendem e estudam, e, por esse motivo, toda ciência é histórica (2003, p. 218). A biologia mesma, na época que Heidegger escreve, estava num movimento de se liberar da física e da química e de questionar a vida em novas bases. Não se tratava simplesmente de um ajuste em teorias físico-químicas, de um acréscimo ou um de rearranjo; a vida mesma é quem impôs, quem pediu outras bases. Quem está na possibilidade questionar a vida em novas bases, de fazer histórica a ciência, portanto, como um modo de seu próprio existir, é o pesquisador atento à origem da questão. Heidegger entende que a relação do pesquisador que está na origem da questão com o objeto pesquisado não é algo dado, que a partir de manipulações de "dados" ele obteria resultados e descobertas que revolucionassem os fundamentos de sua pesquisa. Essa relação indica que à medida que o objeto de pesquisa se dá, pede ao pesquisador que ele também pense a si mesmo enquanto pensa o objeto. Esse pensar a si mesmo ao pensar o objeto consiste em se compreender na multiplicidade de referências, em mundo, portanto, no qual ele e o objeto se encontram, se dão conjuntamente. 
Heidegger já havia escrito algo nesse sentido em Ser e Tempo, ao falar sobre o privilégio ôntico-ontológico do ser-aí, desse ente que nós mesmos somos, como podemos ver na citação abaixo:

As ciências são modos de ser do ser-aí, nos quais ele também se relaciona com entes que ele mesmo não precisa ser. Pertence, porém, essencialmente ao ser-aí: ser em um mundo. Assim, a compreensão de ser, própria do ser-aí, inclui, de maneira igualmente originária, a compreensão de "mundo" e a compreensão do ser dos entes que se tornam acessíveis dentro do mundo. Dessa maneira, as ontologias que possuem por tema os entes desprovidos do modo de ser do ser-aí se fundam e motivam na estrutura ôntica do próprio ser-aí, que acolhe em si a determinação de uma compreensão pré-ontológica de ser. (HEIDEGGER, 2015, p. 49)

Como as ciências são modos em que existimos, os entes são investigados por elas desde nossa existência mesma, e não desde um campo abstrato e indiferente. É, pois, desde a compreensão de si como ser-no-mundo que o homem abre campo para a compreensão de tudo mais. Nesse contexto, a compreensão da vida, em Os Conceitos fundamentais da metafísica, parte da comparação entre a compreensão pré-ontológica que o homem tem de si, enquanto ser-nomundo; e da compreensão pré-ontológica que ele tem dos animais, que, em relação a si mesmo, são pobres de mundo. Essa relação dos animais com mundo, na forma de pobreza, porém, Heidegger precisa tornar clara não como uma proposição filosófica sobre os animais, pura e simplesmente, mas desde a própria biologia.

Todavia, a relação do animal e do mundo, ou mesmo a pobreza ou privação de mundo do animal, como Heidegger descreve, não é pensada pela biologia em seus primórdios. No esforço de se libertar da química e da física a biologia voltou-se para o organismo encerrado na extensão do seu corpo e nesse limite o interrogou sobre a vida. Desde o mecanicismo e até a atualidade, conforme narra Heidegger, a biologia buscou conceituar o organismo em suas menores partes: a célula, o órgão; para chegar ao conceito de organismo como uma soma dessas partes e dos processos por ela realizados, e só então refletir sobre o que significava vida. Para o filósofo,

Este método acreditava - e em parte ainda hoje acredita - poder montar o organismo a partir de um recurso a seus elementos construtivos, sem compreender e ter diante de si antes de tudo o plano de 
construção, isto é, a essência do organismo em sua estrutura fundamental e enquanto o que torna possível o empreendimento da construção. (HEIDEGGER, 2003, p. 298)

Heidegger, porém, não parte de uma suposição da essência do organismo em sua estrutura fundamental para então questionar as bases da biologia. 0 pensador vai até a biologia e busca pensar a partir de seus pressupostos, a partir das definições em que a própria biologia se desenvolveu. Tendo como guia o modo como a questão da vida se desenrolou nas tradicionais teorias da biologia, o autor não lança sobre ela conceitos filosóficos abstratos e vazios, mas pretende se manter em uma resposta a questão mesma. A essência do organismo em sua estrutura fundamental é haurida nesse esforço de interpretação dos conceitos de organismo, órgão, aptidão e se constitui no que Heidegger chama de círculo de desinibição. Nós retornaremos à explicitação desses conceitos mais adiante; mas, de modo resumido podemos dizer que o círculo de desinibição é a totalidade que engendra o devir e a construção do organismo em cada um dos seus estágios. Essa totalidade inclui todo o meio ambiente que lhe desinibe e possibilita que o animal descubra algo com o qual é perturbado e assim se comporte com este algo no interior do seu círculo de desinibição.

Heidegger encontra nas pesquisas do biólogo estoniano Jakob von Uexküll uma mudança na forma de se colocar o problema e no modo de ver, capaz de colocar a biologia em novos rumos. Para o filósofo alemão, as investigações de Uexküll foram um dos passos decisivos na elucidação da conexão do animal com o outro e em como essa ligação é essencial à estrutura do animal enquanto tal (HEIDEGGER, 2003, p. 300). Essa ligação foi vista pelo darwinismo sob o viés, para Heidegger fundamentalmente equivocado, da adaptação, de acordo com a qual "os animais estão simplesmente dados, de que eles se adaptam em seguida, de que eles assumem uma atitude correspondente a um mundo simplesmente dado e de que o melhor é escolhido por eles" (HEIDEGGER, 2003, p. 301). O fato de os animais serem interpretados como entes simplesmente dados, considerados em si mesmos e independentemente do todo no qual eles se dão, guiou as considerações da biologia que procuraram na célula o "elemento originário do vivente" (HEIDEGGER, 2003, p. 299) e permitiu ao mecanicismo a comparação dos órgãos com instrumentos e dos organismos com máquinas. A compreensão do mundo como simplesmente 
dado permitiu a crença de que um ente se dá igualmente do mesmo modo para todos os animais, restando apenas a eles a possibilidade de se adaptarem ou não. Para Uexküll, em Dos animais e dos homens,

Só por excessiva leviandade alimentamos a ilusão de as correlações do sujeito, outro que não nós, com as coisas do seu mundo-próprio existirem no mesmo espaço e no mesmo tempo que as que nos ligam às coisas do nosso próprio mundo humano. Esta ilusão é alimentada pela suposição da existência de um mundo único em que todos os seres vivos estão encerrados. Daí, a convicção geralmente aceite, de que deve haver um único espaço e um único tempo para todos os seres vivos. (UEXKÜLL, 1982, p. 42)

Heidegger viu nas descrições e observações de Uexküll uma similaridade com sua formulação do círculo de desinibição. Ao colocar em questão as estruturas da conexão entre o ser vivo e seu meio ambiente, Heidegger relaciona as proposições de Uexküll com a abertura dos seres vivos para o outro, que lhe perturba e desencadeia um comportamento.

O animal encontra o outro, no sentido de algo com o qual é perturbado, segundo Heidegger, em meio ao seu ser-apto-para: sua aptidão (aptidão para comer, para caçar, para correr), a qual é mais originária em relação aos órgãos e ao organismo. Para que possamos compreender como isso é possível, como os animais encontram o outro em meio ao seu ser-para, apresentaremos, de forma sucinta, alguns pontos das intepretações e desconstruções heideggerianas dos tradicionais termos em que a biologia buscou pensar a vida.

Vemos, em Os Conceitos Fundamentais da Metafísica, que, para o pensador, o animal não pode ser dito, essencialmente, como uma soma de órgãos que possuem aptidões, encapsulados em um organismo que pode vir a entrar em contato com outros entes. Ao contrário, são as aptidões que criam para si órgãos: "não podemos dizer que o órgão possui aptidões, mas sim que a aptidão possui órgãos" (HEIDEGGER, 2003, p.255). É desde o enxergar, por exemplo, que olhos são criados para essa aptidão. Essa proposição de Heidegger, que vai assim na contramão do que usualmente compreendemos, de que enxergamos porque temos olho, é feita no contexto de uma crítica que o autor dirige à interpretação dos órgãos como utensílios, tal como preconizava as teorias mecanicistas. 0 utensílio caneta, exemplifica o autor, serve para escrever. Do mesmo modo compreendemos o olho, como se por si mesmo tivesse aptidão para enxergar. Sua 
aptidão, no entanto, escreve Heidegger, é desde sua pertença ao organismo. É o organismo que possui aptidões, desde as quais provém os órgãos. Essa complexa inversão que mostra o serapto como formador de órgãos, é exemplificada pelo autor em uma descrição dada pela biologia da estrutura dos organismos inferiores, considerados até então como as unicelulares amebas e infusórios:

Justamente não os animais mais elevados, mais complexos e mais solidamente constituídos, mas os inferiores, assim chamados animálculos unicelulares protoplasmáticos, as amebas e infusórios, eles, que não possuem aparentemente nenhum órgão, são, vistos filosoficamente, os mais apropriados para proporcionar-nos uma inversão do olhar na essência do órgão. [...] Os animálculos protoplasmáticos são desprovidos de forma e de estrutura. Eles não apresentam nenhuma figura animal fixa; é por isso que falamos em "amebas", do grego amoibê, "permutação". Eles sempre precisam formar por si mesmos seus órgãos necessários, para então aniquilá-los uma vez mais. Neste sentido, seus órgãos são órgãos instantâneos. Assim se dão as coisas junto às amebas. Em meio aos infusórios, alguns órgãos subsistem. Em verdade, todos os órgãos, que têm a ver com a preensão e locomoção subsistem nos infusórios, enquanto os órgãos vegetativos, que servem à digestão, não são fixos ( $p a$ ramecium). Em contrapartida, os outros órgãos estão atrelados ao protoblasma. Forma-se sempre e a cada vez "em torno de cada pequeno bocado uma bexiga que se torna primeiramente boca, então estômago, então intestino, e, por fim, ânus"2. Temos, assim, uma determinada série de órgãos que se aniquilam em uma determinada ordem. Daí resulta de maneira concludente: aptidões para comer, para digerir, são mais antigas que os respectivos órgãos. (HEIDEGGER, 2003, p. 257)

Vemos, nessa longa passagem, um exemplo na própria biologia da proposição heideggeriana segundo a qual a aptidão cria órgãos. Estômago, intestino e ânus nesses animais inferiores, são assim constituídos e aniquilados conforme são requisitados, no tempo que são requisitados. Ou seja, para se alimentarem e para a digestão são criados estômagos e intestinos; não o oposto: porque tem estômago e intestino eles comem e digerem alimentos. Para Heidegger, os órgãos não são autônomos, mas encontram-se sempre a serviço de aptidões até que a própria aptidão o libere do serviço em que ele foi posto. 0 órgão olho, que pertence e serve à aptidão do ver, só pode estar a serviço de ver por que a aptidão mesma de ver está a serviço de e, enquanto está a serviço de, pode pôr o órgão também a serviço. 0 surgimento do olho e do ver regula e circunscreve a visão, ou seja, a aptidão, nela mesma.

\footnotetext{
${ }^{2}$ Conforme citação do autor: J. v. Uexküll. Theoretische Biologie. 2ª ed. totalmente revisada. Berlim, 1928 , p. 98.
} 
Ao se transferir para adiante de si (a visão vendo), a aptidão se transfere para o interior do seu para-que próprio. De acordo com o pensador, essa transferência ou translação da aptidão indica um movimento, uma pulsão: “Este impelir-se e ser impelido para o interior de um para-quê só é possível no que é apto, se o ser-apto é acima de tudo pulsional" (HEIDEGGER, 2003, p. 262). Impulsionada, a aptidão forma órgãos que se mantêm sempre a serviço. A pulsão impele o ser-apto para o seu para-que. Ela é antecipadamente regulativa à aptidão, ordenando os impulsos possíveis para a respectiva aptidão no impelir se adiante. Estes impulsos, segundo Heidegger, não são resultados provocados pelos movimentos vitais, tais como alimentação ou locomoção. Eles desde sempre transpassam e atuam em todo o movimento do ser vivo (HEIDEGGER, 2003, p. 263).

Heidegger descreve que a aptidão se impele adiante de si mesmo perfazendo uma dimensão no interior da qual o para-que dos seus órgãos se dá, e nisso, nesse movimento, ela está junto de si. Isso significa que, para o autor, a visão que, pulsionada, vê com o serviço dos olhos, não se esgota aí; ela se mantém junto a si, enquanto visão mesma. Impelido pelas aptidões em direção a algo o animal é próprio a si, como podemos ver nessa citação:

A propriedade do animal diz: o animal, e, de início, seu específico ser-apto para..., é próprio a si. Ele não se perde, conquanto um ímpeto pulsional em direção a algo deixe a si mesmo para trás. Ao contrário, ele retém-se justamente em meio à pulsão e é ele mesmo, como se diz, nesta pulsão e neste impulsionar. (HEIDEGGER, 2003, p. 268-268)

De acordo com Heidegger, a serventia do órgão é um estar a serviço de, atrelado a aptidão. Heidegger faz uma distinção entre o servir-para da aptidão e da prontidão. 0 utensílio ter prontidão para algo significa que ele está pronto e pode ser usado. Ele não perde sua serventia caso não esteja efetivamente em uso: a caneta está pronta para escrever ainda que não esteja sendo usada para tal. Já órgãos não podem não estar a serviço, eles não estão prontos para o uso, mas estão sempre em uso, estão sempre à serviço da aptidão. Nas palavras de Heidegger "Os olhos não são úteis para o ver, assim como a caneta para o escrever, mas o órgão encontrase a serviço da aptidão que o forma. Enquanto tal, a coisa fabricada pronta é útil para... 0 órgão que surge na e a partir da aptidão está a serviço de" (HEIDEGGER, 2003, p. 259). A aptidão se 
mostra anterior ao órgão, portanto, à medida em que o requisita e o forma em seu para-que ao impelir-se adiante de si.

Após essas considerações o autor chega à noção de organismo como esse ser que se articula em aptidões criadoras de órgãos e que se retém junto a si mesmo devido ao caráter de propriedade da aptidão. Essa noção indica que organismo não é um apanhado de aptidões. Ele não é um suporte que comporta aptidões, equipado com elas, “[...]seu ser é poder, a saber, poder articular-se em aptidões, isto é, em certos modos de permanecer próprio a si de maneira pulsional e a serviço de" (HEIDEGGER, 2003, p. 269). Para o filósofo, o ser-apto, o ser possível onde outros são descobertos, indica mais expressamente algo em direção a essência da vida do que a tradicional concepção de organismo: "Só o que é e continua sendo apto vive; o que não é mais apto, abstraindo-se completamente do fato de se fazer ou não uso da aptidão, não vive mais" (HEIDEGGER, 2003, p. 270).

A aptidão é impulsionada adiante de si no interior do seu para-que e nesse movimento se retém. Também o organismo, de acordo com Heidegger, como esse articular-se em aptidões, se mantém nesse carácter de propriedade, no sentido de próprio a si, retido junto a si, como vimos na citação anterior (HEIDEGGER, 2003, p. 268-268). Em seu comportamento face a algo diverso o animal mantém-se preso a si. Este movimento no qual o animal, face ao diverso, mantém um comportamento, impulsionado pelas aptidões, que impelidas retém a si, o autor chama de perturbação (Benommeheit):

A perturbação é a condição de possibilidade para que o animal se comporte segundo sua essência em um meio ambiente, mas nunca possa se comportar em um mundo [...] A perturbação não é um estado qualquer que acompanha o animal: um estado no qual ele por vezes recai. Ela tampouco é um estado no qual ele está de maneira duradoura. Ela é, sim, muito mais a possiblidade interna do ser animal mesmo. (HEIDEGGER, 2003, p. 274)

A perturbação que Heidegger descreve aqui não deve ser confundida, alerta o autor, com a perturbação em que por vezes nós estamos. Como um momento essencial da animalidade, ao animal não é possível não ser perturbado. 0 modo de ser perturbado do animal significa pertencer ao ser-apto, “[...] isto é, ao dispor-se em si e transpor-se para o interior de si de maneira pulsional e marcada pela estrutura 'a serviço de'” (HEIDEGGER, 2003, p. 274). Na perturbação 
o animal é absorvido pelos correlatos das aptidões, “O ver é o ver do que se viu, o ouvir é o ouvir do que se ouviu" (HEIDEGGER, 2003, p. 275). Os animais, segundo Heidegger, se ligam as coisas tão somente à medida que elas o afetam, à medida que são correlatas às suas aptidões. Não é que o animal simplesmente não veja as coisas, o cachorro salta poça de água, procura sua comida, mas tal relação só se dá em meio à sua perturbação. Diferentemente do modo como nós já desde sempre, de acordo com o filósofo, encontramos o ente enquanto tal no contexto de uma totalidade de referências possíveis desde mundo.

Assim, se o organismo é o que é por ser-apto e articular-se em aptidões que se impelem para o que as afeta no interior do seu para-que, não é certo dizer que a vida se limita a extensão do corpo do organismo, mas sim a todo o meio ambiente que lhe desinibe e o torna possível ser tal qual é, ou seja, ao círculo de desinibição. As coisas às quais o animal se liga ao se comportar desde suas aptidões são abertas para ele nesse comportar-se. Pois "Isto com o que o comportamento animal se liga é de um tal gênero que este comportamento é aberto para ele. Este outro é admitido no interior da abertura do animal de uma maneira que merece a designação de desinibição" (HEIDEGGER, 2003, p. 291). 0 animal só vai se deparar com alguma coisa desde que ela afete sua aptidão, do contrário não. A forma como o outro afeta a aptidão, a ponto de abrir o comportamento do animal, é o que Heidegger chama de desinibição. Esse aspecto é importante porque o que afeta a aptidão de um animal não é o mesmo que afeta a aptidão de outro animal. "[...] à medida que o animal se envolve no círculo, ele abre e traça o espaço, no interior do qual este ou aquele elemento desinibidor pode atuar" (HEIDEGGER, 2003, p. 291). Cada animal possui um círculo de desinibição próprio, ainda que esses círculos se insiram um nos outros. Nós mesmos, como veremos adiante, experimentamos em nosso modo de ser uma certa inserção no interior do círculo de desinibição dos entes vivos. Isso é o que Uexküll chama, grosso modo, de mundo-próprio ou mundo circundante (Umwelt) de cada ser vivo: o modo como um molusco, um inseto ou um mamífero vê e age no mundo é diferente para cada um.

De acordo com Heidegger,

A perturbação é privação, e, em verdade, privação essencial. Não apenas uma privação duradoura ou temporária da possibilidade de abertura do ente. Um animal só pode comportar-se, mas nunca está em condições de perceber algo enquanto algo; o que não diz nada contra o fato de o animal ver ou 
mesmo notar. No fundo, porém, não se pode sequer dizer que o animal é capaz de notar. (HEIDEGGER, 2003, p. 296)

O animal descobre algo com o qual é perturbado e se comporta com este algo no interior do seu círculo de desinibição, mas é privado de descobrir esse algo enquanto ente, e nessa privação ele é pobre de mundo. 0 animal está aberto ao outro, mas não pode compreender este outro enquanto ente.

Para ilustrar como isso acontece, Heidegger cita um exemplo dado por Uexküll (2003, p. 276) que retomaremos de forma resumida: As abelhas voam de uma flor para outra, de um trevo para outro, sugam a gota de mel que encontram e voam dali, voltando para a colmeia. Poderíamos dizer, sugere o filósofo alemão, que a abelha voa dali porque sugou todo o mel, porque o mel não está mais presente. No entanto, Heidegger questiona se podemos dizer, como podemos dizer, que a abelha constatou que o mel não estava mais presente e simplesmente dado. De modo algum, ele responde. Esse ato realizado pela abelha é caracterizado como um comportamento e um comportamento não é a "assunção de uma atitude por parte da abelha em relação ao mel presente ou não presente" (HEIDEGGER, 2003, p. 277), mas um movimento pulsional, através do qual podemos ver que "tudo que impele o animal é caracterizado por um já ter sido impelido de maneira pulsional" (HEIDEGGER, 2003, p. 272). Como vimos anteriormente, o comportamento animal caracteriza o que o autor chama de perturbação. Nesse comportamento/perturbação o animal está preso, retido em si mesmo. 0 que difere radicalmente do sentido em que este mesmo termo aparece em Ser e Tempo: como modo em que existimos, em que assumimos uma atitude em relação ao ente que nos vêm ao encontro. 0 animal não está na possibilidade de, de acordo com o autor, assumir uma atitude em frente ao que vem ao encontro, tal como ocorre conosco. Ele é absorvido pelo outro nesse comportar-se. Tanto o voar até a flor, o sugar o mel e o parar de sugar o mel não se dão em virtude da presença simplesmente dada desses elementos para a abelha, mas esses comportamentos se dão em virtude das pulsões e inibição das pulsões que a constitui e das quais ela é refém. Não podemos dizer que a abelha nota algo enquanto algo, em direção a qual ela assume uma atitude. Pois, segundo Heidegger, “[...] é preciso lembrar que o notar - abstraindo-se de qualquer outra coisa - é sempre um notar 
de algo para algo, em vista de algo [...]" (HEIDEGGER, 2003, p. 282). Para o autor, a ligação que o animal tem com a flor, com o mel, com a colmeia, não é uma percepção desses entes enquanto entes num horizonte de significância em virtude de seu próprio ser, mas um já estar num comportamento, sendo absorvido por esse outro que ele encontra ao ser por ele perturbado. Um exemplo mais curioso disso, dado pelo pensador, refere-se à um experimento no qual um recipiente cheio de mel é colocado diante da abelha (HEIDEGGER, 2003, p. 277). Não podendo sugar todo mel de uma única vez a abelha inicia sua atividade e depois para, deixando o mel restante no recipiente. No entanto, nesse experimento é seccionado o abdômen da abelha durante o ato de sugar, e ela continua sugando sem parar enquanto o mel escorre por trás, na parte seccionada. 0 que Heidegger pretende mostrar com esse exemplo é que a abelha não percebeu que tinha muito mel presente, que ela poderia ou não dar conta, e nem mesmo que seu abdômen foi retirado, "Ela é simplesmente presa pela comida. Este aprisionamento só é possível onde há um movimento pulsional. [...] Justamente o aprisionamento pela comida impede que o animal se contraponha à comida" (HEIDEGGER, 2003, p. 277-278). 0 outro, ao que ela se liga, já estava ligado a ela na pulsão que a impele. A pulsão já requer o outro sem que, no entanto, ele seja descoberto enquanto outro. Isso que a abelha é, isso que os animais são, o que os torna vivos, a essência da vida por consequência, passa por essa ligação: do comportamento e do com o que o comportamento se comporta. Vemos assim que os animais são abertura, mas abertura de quê? Vemos em Heidegger que,

O comportamento do animal não se liga jamais - como poderia parecer-nos - a coisas simplesmente dadas, mas se envolve em seu círculo de desinibição, no interior do qual está inscrito previamente o que pode atingir o seu comportamento e lhe dar ocasião. Porque este envolvimento pertence ao animal, ele sempre traz consigo a partir de si mesmo o círculo de desinibição e o carrega consigo por toda a vida aonde quer que vá. Mais exatamente - sua vida é justamente o girar em torno deste círculo, em cuja circunscrição pode vir à tona uma multiplicidade determinadamente articulada de desinibições. Todo animal envolve-se nesse círculo de desinibição. No entanto, este envolvimento não tem um lugar ulteriormente, depois de ele já ter vivido um certo tempo como animal. Ele pertence muito mais à organização mais interna do animal e à sua figura fundamental. A absorção do animal sempre e a cada vez pelo todo aponta para a mesma direção das desinibições possíveis no interior de seu círculo. A absorção é aberta para a multiplicidade de desinibições. Este estar-aberto não implica, contudo, a abertura de um ente enquanto tal, um ente ao qual o comportamento poderia se ligar. Essa absorção aberta é em si uma privação da possibilidade da percepção do ente. Neste 
envolver-se no círculo reside o estar-aberto e absorvido por ele - não em uma assim chamada 'interioridade' do animal, mas no círculo da compulsão das pulsões que se abrem. (HEIDEGGER, 2003, p. 292)

Vemos, nessa citação, que Heidegger descreve os animais como abertura para o círculo de desinibição, e não para entes simplesmente dados. 0 que se dá no interior desse círculo Heidegger diz ser o desinibidor de uma pulsão, não um ente simplesmente dado. Quer dizer que o modo como o outro é descoberto, a abertura, já significa o modo de ser do próprio animal. Ou seja, o outro não precisa ser descoberto como ente para que para haja uma ligação. Diante da comida, estando com fome, o animal come. 0 cachorro, por exemplo, não percebe a comida como comida, como algo, ele não pode não comer se estiver com fome e saudável. Diferentemente do modo como a comida, enquanto comida, nos vem ao encontro. 0 cachorro, até onde sabemos, não faz regime, não avalia o valor nutritivo da comida, ou sua origem, nem se há comida suficiente para os demais cachorros. Entendemos que, para Heidegger, qualquer que seja a relação que o cachorro tem com a comida essa relação é totalmente outra da relação que nós temos. A comida desinibe nele a pulsão que ele já tem, é, de comer, e ele come. Nesse comportamento ele é absorvido e se retém. 0 modo de ser da animalidade então, é marcado por essa abertura que, por se tratar de um círculo, não vai de um polo ao outro, de um ente que se comporta em direção a outro ente, mas da própria abertura enquanto tal.

Heidegger entende, portanto, que ao falar de "mundo circundante" o que Uexküll tem em vista é essa estrutura do círculo de desinibição, e não o modo como superficialmente esse termo pode ser usado também na biologia. Para Heidegger, "Uexküll é justamente aquele entre os biólogos que sempre acentua novamente e com toda incisividade que isto, com o que o animal está em ligação, é dado de outro modo do que para os homens" (HEIDEGGER, 2003, p. 302). Em Ser e Tempo, ao falar como o termo "mundo circundante" é utilizado, Heidegger diz que

A formulação, hoje muito em voga, de que o homem "tem seu mundo circundante" nada diz do ponto de vista ontológico, enquanto esse "ter" permanecer indeterminado. É que, em sua possibilidade, "ter" se funda na constituição existencial do ser-em. Sendo essencialmente desse modo, o ser-aí pode, então, descobrir explicitamente o ente que lhe vem ao encontro no mundo circundante, saber algo a seu respeito, dele dispor, ter "mundo". A formulação "ter um mundo circundante", tão trivial do ponto de vista ôntico, é, do ponto de vista ontológico, um problema. Para resolvê-lo é imprescindível 
determinar, primeiro, de maneira suficiente e ontológica, o ser do ser-aí. Porque a biologia se vale dessa constituição de ser - sobretudo depois de K.E. von Baer - não se deve deduzir um "biologismo" do uso filosófico dessa constituição. É que também a biologia, enquanto ciência positiva, não pode encontrar e determinar essa estrutura. Ao contrário, deve pressupô-la e dela fazer um uso constante. Em si mesma, essa estrutura só poderá ser filosoficamente explicitada como um a priori do objeto temático da biologia, depois de ter sido compreendida como estrutura do ser-aí. Apenas orientandose pela estrutura ontológica assim concebida é que se poderá definir a priori, através de uma privação, a constituição de ser da "vida". Tanto do ponto de vista ôntico como ontológico, o ser-no-mundo, enquanto ocupação, tem a primazia. (HEIDEGGER, 2015, p. 104).

Heidegger não procura definir a constituição de ser da "vida" em Ser e Tempo, e só o faz em Os conceitos fundamentais da metafísica como um meio para alcançar o significado de mundo para o ser-aí. Não que a vida seja inferior, mas essa questão, tanto quanto qualquer outra, funda-se na ontologia do ser-aí, como modo de seu ser. Para o autor é desde a compreensão da estrutura ontológica do ser-aí que estamos em condições de problematizar a vida. Isso porque, como vimos no início do texto, temos a tendência de, cotidianamente, interpretar os entes de modo nivelador, como isolados e indiferentes, igualmente dispostos. Assim, quando estamos diante da questão pelo modo de ser dos entes vivos em geral, respondemos, estabelecemos definições, fixando em teorias as tradicionais interpretações hauridas do cotidiano e compreendemos que isso ao que ser vivo se liga é algo simplesmente dado, que ele mesmo é algo simplesmente dado e que a vida não passa de algo simplesmente dado no mundo ou que, no limite, se confunde com nosso próprio modo de ser.

Assim, quando Uexküll afirma que aquilo a que o animal se liga é diferente para os homens, Heidegger diz que é necessário ir além: "A questão não é se e como o animal toma o que é dado de outro modo para os homens, mas se o animal em geral pode ou não perceber algo enquanto algo, algo enquanto ente" (HEIDEGGER, 2003, p. 302). Porque dizer que o animal toma o que é dado de outro modo, é ainda dizer que o animal, tal como o homem, toma algo como algo. É a partir da compreensão de mundo do ser-aí, que torna possível que ele interprete algo enquanto algo, que Heidegger compreende a privação de mundo do animal, que se abre a algo sem, no entanto, o interpretar enquanto tal.

Na ordem de uma possível apreensão e interpretação, a biologia como "ciência da vida" funda-se, embora não exclusivamente, na ontologia do ser-aí. A vida é um modo próprio de ser, mas que, em 
sua essência, só se torna acessível no ser-aí. A ontologia da vida se exerce seguindo o caminho de uma interpretação privativa; ela determina o que deve ser, de modo que uma coisa possa ser apenas vida. A vida não é nem coisa simplesmente dada nem ser-aí. 0 ser-aí, por sua vez, não poderá ser determinado ontologicamente, tomando-o como vida - (indeterminada do ponto de vista ontológico) à qual ainda se acrescenta uma outra coisa. (HEIDEGGER, 2015, p. 94)

Tanto nesta citação de Ser e Tempo quanto na anterior, vemos repetido o termo 'privação', que é como Heidegger se refere à pobreza de mundo dos animais. Os animais não são pobres de mundo porque se abrem menos ou mais superficialmente ao mundo. A intepretação privativa, como podemos ver nessa citação, refere-se a retirar da vida as interpretações que nela foram se fixando e que permitiram sua interpretação desde um horizonte de subsistência de entes simplesmente dados. Partindo do mundo como constituinte do ente que nós mesmos somos, como totalidade conjuntural em virtude de nosso próprio existir, o modo como podemos interpretar a abertura dos animais aos outros entes com os quais eles se comportam, diz Heidegger, deve ser interpretado de modo privativo, ou seja, desconstrutivo. Nós interpretarmos o ente enquanto ente e, lidando com os animais, interpretamos aquilo com o que eles se comportam enquanto ente, mas não podemos dizer do animal, ele mesmo, que ele interpreta de algum modo; não podemos definir o que para ele significa esse ente ao qual ele se abre. De acordo com Reis, “Determinar o estatuto do 'objeto' que se apresenta na abertura própria da vida é determinar o estatuto ontológico do próprio organismo, da vida como tal” (REIS, 2012, p. 496). Aquilo a que o vivente está aberto e que o constitui enquanto tal perfaz o "mundo" que Heidegger pretende comparar. No entanto, como dizer esse 'objeto' para o animal senão de uma forma negativa em comparação ao modo como nós compreendemos? Dizer que o animal é privado de mundo só pode se dar por comparação com nosso modo de ser, e não da animalidade ela mesma. Nas considerações sobre a animalidade e sobre a essência da vida é nossa compreensão de ser que está à base; entendermos os animais como seres vivos, só é possível porque existimos como compreensão de ser. A comparação que serve de base para Heidegger discutir o problema da vida se mostra então nessa interpretação privativa. Assim, de acordo com Heidegger, 
A dificuldade do problema reside no fato de o nosso modo de questionamento sempre impor a interpretação desta pobreza de mundo e deste envolvimento característico do animal no círculo a partir do pressuposto de que isto com o que ele se liga e o modo como ele se liga é um ente. Nós colocamos aqui a questão como se esta ligação mesma fosse uma ligação ontológica aberta para o animal. Uma vez que isto não procede, somos levados à tese de que a essência da vida só é acessível no sentido de uma consideração desconstrutiva; o que não significa que a vida seja menos valiosa ou esteja em um nível inferior ao ser-aí humano. A vida é muito mais um âmbito, que possui uma riqueza de abertura tal que o mundo humano talvez não conheça de forma alguma. (HEIDEGGER, 2003, p. 292)

Vemos que a vida para Heidegger não pode deixar de ser considerada como problema, não obstante todas as elucidações e investigações que tenha somado à biologia. Na busca pela essência da vida dizer aquilo que ela não é, ao invés de a definir, não significa, de modo algum, uma deficiência ou insuficiência na nossa compreensão: significa um mistério, como propõe Reis (2012), que parece descrever a estrutura ontológica da vida. Uma comparação da vida com nossa existência em uma interpretação privativa é, para Heidegger, o modo mais originário no qual podemos descobrir a vida como ela se dá.

Heidegger não compara nossa existência com o modo de ser dos viventes como se ambos estivessem igualmente dispostos lado a lado e nós tivéssemos uma supremacia de problematizá-los. De acordo com Heidegger, nós já desde sempre estamos presos à natureza vivente devido ao nosso modo de ser-transposto. Como assim? A abertura característica dos animais possibilita que a nossa relação fundamental característica com o vivente, de acordo com Heidegger no parágrafo 49 e novamente no parágrafo 66 de Os conceitos fundamentais, seja a possibilidade de transposição para o interior do seu círculo de desinibição. Essa possibilidade de transposição, diz o autor, é "o caráter específico do reino animal" (HEIDEGGER, 2003, p. 318). Como vimos anteriormente, ainda que cada animal possua um círculo de desinibição próprio, esses círculos se inserem um nos outros:

Todo este contexto de abertura dos círculos envoltórios a partir da perturbação não é, então, apenas de uma riqueza de conteúdo e de ligações descomunal e por nós somente suspeitada. Em tudo isto, ele ainda permanece fundamentalmente diverso da abertura do ente, como este vem ao encontro do ser-aí humano formador de mundo. (HEIDEGGER, 2003, p. 317-318)

Nós também, de acordo com Heidegger, experimentamos uma transposição muito específica e limitada para o interior do círculo de desinibição dos animais. Essa transposição, 
descrita por Heidegger logo no início do seu comentário sobre a animalidade e que se repete considerações finais (quando ele então passa a tratar especificamente da formação do mundo para o ser-aí humano), se mostra como o modo originário nosso de descoberta dos viventes. Pois, a partir do exposto pelo filósofo alemão, em Os conceitos fundamentais da metafísica, percebemos que os animais não vêm ao nosso encontro, originariamente, na ocupação: nem como entes simplesmente dados e nem como utensílio; eles também não têm o mesmo modo de ser dos seres-aí humanos, descobertos na preocupação. Isso mesmo é o que nos mostra a pergunta pela possibilidade de nos transpormos para o interior de uma pedra ou para o interior de outro ser-aí humano. A descoberta de cada um: homem, animal e coisa; se dá de maneira diversa e, como podemos acompanhar no texto, a transposição não se mostra possível nos outros dois casos. Podemos dizer que somos essencialmente ser-com os outros humanos, ser-junto aos entes intramundanos e ser-transposto aos viventes. No parágrafo 49 Heidegger nos diz que a transposição consiste no fato “[...] de nós mesmos justamente sermos nós mesmos, e, assim somente, criarmos a possibilidade de, mesmo enquanto outros - diante do ente -, podermos acompanhá-lo" (HEIDEGGER, 2003, p. 234).

\section{Limites e liberdade da questão da vida}

Não acompanhamos os animais por supostamente podermos pensar como eles, de nos pormos no lugar deles, mas tão somente desde nosso modo próprio de ser, desde nossa existência, desde o mundo que nos constitui. Disso, entendemos, resulta um limite na compreensão da vida nela mesma, uma vez que a dinâmica da vida não se limita à nossa formação de mundo. No entanto, entendemos justamente a compreensão desse limite como a possibilidade de interpretarmos a vida a cada vez, sem fixá-la em fórmulas, cálculos e medidas, não obstante às formulações, cálculos e medições com as quais lidamos e, tendemos a continuar lidando com ela. Pois ainda que, conforme o progresso das ciências, o cálculo, a mensurabilidade, a matematização dos entes vivos possibilitem produzir órgãos em escala e que esse fato pareça tornar nulas 
as críticas de Heidegger às teorias mecanicistas ${ }^{3}$, entendemos que a junção desses órgãos assim produzidos, que funcionam também no para que eles foram produzidos, não produz vida. É desde a vida que esses órgãos são requisitados e têm seu desempenho avaliado.

Como dissemos no início do artigo, o problema da vida para Heidegger não se apresenta como questão principal em suas obras, com as quais trabalhamos e, também, não têm nenhuma resposta conclusiva por parte do filósofo. 0 que justamente iria contra a proposta heideggeriana, de liberar os conceitos de sedimentações hauridas ao longo da tradição e recuperar o instante originário, e sempre dinâmico, em que eles se deram. Por esse motivo a questão pela vida é tão importante e, seus desdobramentos podem mesmo confrontar outras questões investigadas pelo autor, como sugere Reis em um de seus trabalhos sobre o tema (2010). Confrontações essas que pensamos poder ser tema para futuros artigos.

${ }^{3}$ Sobre a crítica heideggeriana ao mecanicismo e à irrestrita matematização dos seres vivos ver Reis (2017, p. 691 710). 


\section{Referências}

HEIDEGGER, Martin. Ser e Tempo. Trad. Márcia Sá Cavalcante. 10ª ed. Petrópolis, RJ: Vozes; Bragança Paulista, SP: Editora Universitária São Francisco, 2015.

HEIDEGGER, Martin. Os conceitos fundamentais da metafísica: mundo, finitude, solidão. Trad. Marco Antônio Casanova. Rio de Janeiro, RJ: Editora Forense Universitária, 2003.

REIS, Robson Ramos. A interpretação privativa da vida e a relação circular entre Biologia e Ontologia. Revista de Filosofia Aurora, Curitiba, v.22, n.31, p. 423-435, 2010

REIS, Robson Ramos. Heidegger: a vida como possibilidade e mistério. Revista Filosófica Aurora, Curitiba, v. 24, n.35, p. 481-507, jul./dez.2012.

REIS, Robson Ramos. Heidegger e os limites da matematização no conhecimento dos organismos vivos. Revista Kriterion, Belo Horizonte, no 138, p. 691-710, set./deze. 2017.

SOUZA, Elaine Cristina Borges de. A teoria de mundo-próprio de Jakob von Uexkull: entre a metafísica e o naturalismo. Vitória, UFES. Dissertação de mestrado, 2012.

TORRES, João Carlos Brum. Sobre a distinção heideggeriana entre órgão e instrumento e a revolução biológica contemporânea. Revista Filosófica de Coimbra, v. 19, p. 315-340, 2010.

UEXKULL, Jacob von. Dos animais e dos homens. Trad. Alberto Candeias e Aníbal Garcia Vieira. Lisboa: Edições Livros do Brasil, 1982

Recebido em: 25/3/2021

Aprovado em: 02/7/2021

\section{Josiane Paula da Silva}

Mestranda do Programa de Pós-Graduação em Filosofia da Universidade Estadual do Oeste do Paraná UNIOESTE, na linha de pesquisa: metafísica e conhecimento. 